\title{
Christopher R. Henke: Cultivating Science, Harvesting Power: Science and Industrial Agriculture in California
}

\author{
The MIT Press, Cambridge, Massachusetts, 2008, 226 pp. ISBN978-0-262-08373-7
}

\author{
William H. Friedland
}

Published online: 8 October 2009

(c) The Author(s) 2009. This article is published with open access at Springerlink.com

Christopher Henke certainly got the title of his book right; how, by "cultivating science," California's industrial agriculture has "harvested power" and wealth. This study of Cooperative Extension (aka "Agricultural Extension") appears at a time in which Extension, and publicly-supported in the US generally, have become increasingly beleaguered. This is mentioned but is not the burden of this study which is focused on the history and current state of Extension in Central California, particularly Monterey County. Recognizing the role of Extension in providing scientific applications to existing agriculture, Henke also mentions Extension's primary constituency, California's growers and agricultural workers' roles in Extension's work, albeit as a sideline.

This is a methodologically sound book bringing several less familiar sociological orientations to bear. While agrifood researchers have utilized political economy, actor network theory, and several other approaches, Henke introduces science-technology-society (STS) and ethnomethodological perspectives which give him a distinctive view. Unlike most social science analyses of Extension that view it as a captive of agribusiness, Henke sees Extension engaged in an effort to repair the continuing problems of American agriculture. Henke derives repair from ethnomethodology as "the work of maintaining this system in the face of constant change" (p. 10).

Consisting of seven chapters, the introduction sets out the argument on repairing industrial agriculture. The next two chapters deal historically with Extension as part of the American agrarian ideal and how it fitted into California's

W. H. Friedland ( $₫)$

Oakes College, University of California, Santa Cruz, CA 95064, USA

e-mail: friedla@ucsc.edu industrial agricultural system. Chapter 3 makes clear Extension's focus on "progressive" growers, that adjective being defined as being open to and avid for scientific applications to increase output, not to be confused with any notion of "progress" in its political sense. Chapter 4 deals with Extension's role vis-à-vis farm labor and sugar beet mechanization. Chapter 5 studies field trials as "making a place for science" in industrial agriculture. The final two chapters examine Henke's introductory explanation of "industrial agriculture as an ecology of power" and, briefly, what he sees as the future of American agriculture.

A major question therefore emerges: coming from an STS background with ethnomethodological overtones, and explicitly concerned with integrating them with the sociology of agriculture, does Henke provide a convincing analysis of Extension? If he is to make a compelling argument, Henke should deal with the long-standing analysis of Extension as a subservient agency of industrialized, capitalized agribusiness. By his own evidence, he fails to do this. If anything, the examples he provides made clear, to this reviewer, that Extension agents know very well who butters their bread (and the social machinery by which it is buttered). Yet his STS and ethnomethodology produce interesting different approaches even if they are less convincing in fulfilling the title of his book.

Chapter 5, for example, provides a useful examination of how field trials, applying scientific knowledge to production, have to be carefully framed and managed to be successful. Here the intermediary role Extension agents play between growers-always anxious to improve output but always worried about outcomes-and scientists is carefully elaborated. To his credit, Henke also acknowledges the importance of field workers as data producers, something he learned by comparing them to laboratory assistants. This he draws from his STS background, 
recognizing that both are essentially socially "invisible," obliterated by others involved in agricultural and science production.

Chapter 4 on farm labor, less convincing, deals with the introduction of mechanized sugar beet harvesting. The chapter is useful because Henke found an archive of company records that had "disappeared" and used them to construct his case study. Since no detailed history has previously appeared, this case has utility. However, the chapter hardly buttresses Henke's contention about Extension's role as a "repairer"; this reader saw it again as Extension as the servant of agribusiness.

Henke's central argument centers on Extension engaging in the work of "repair." Repair of what and for whom? Henke shows that he is fully aware of the political economy of California agriculture; this is manifested not only by the book's title but also in Chap. 6 where he shows how Extension agents must adapt to the wishes of agribusiness. Henke writes: "Using the case of farm advising, my aim in this chapter is to demonstrate that advisors $d o$ act as agents of social change but also to show that their work is tightly circumscribed by the larger political economy of the farm industry and the regulatory state" (p. 145, emphasis in the original).

Two case studies illustrate the pitiful weakness of Extension as an agent of social change. The first concerns over-application of synthetic nitrogen fertilizer as crop insurance, producing nitrate contamination of groundwater. Despite complaints from regulatory agencies and the development of a "quick test" by an Extension specialist and county Extension agents that could help alleviate the contamination, grower resistance made Extension personnel walk away from the issue. The second case, "Watching the weather to reduce pesticide use" (pp. 160-167) is more complex but direct. This involves the search for a high-tech solution to an endemic problem of downy mildew in Salinas Valley lettuce fields. It engaged a complex of actors: Lettuce Research Board members (who provided the funding), Davis campus researchers including an crucial scientific modeler, the local Extension plant pathologist, and companies anxious to sell high-tech equipment to growers. Each group/agent had differential interests in whether to proceed with the system.

The Lettuce Research Board and the equipment manufacturers wanted to proceed with extensive testing of the research. When the Davis modeler refused because of uncertainties about the model, she was defunded. The local plant pathologist, unfamiliar with modeling, was pressured to proceed with the project. He experienced the pressure but remained uncomfortable with the results and his own inexperience with modeling. He commented to Henke that, while things usually work well, in this case they did not, creating "hard feelings" (p. 165).

The protagonists for proceeding publicly reported the system as working well and increasing productivity. In one situation, the pathologist, still not in agreement, sat in the audience at a national conference of plant pathologists when positive results were reported. "Although the plant pathologist was tempted to 'make a scene' and challenge the scientist's presentation, he maintained his diplomatic stance" (p. 166). That is (and Henke is equally diplomatic), the plant pathologist remained silent, an example of Henke's argument for the ecology of power that stands in contrast to his argument about Extension's role in "repair."

In the final chapter on the future, Henke reflects a "scientific optimism" that struck this reviewer as having little relationship to what has come before. He acknowledges that private sources have a "strong influence" on Extension's research agenda (p. 176), yet believes that Extension will play a continuing role, perhaps as has happened in some countries, as even more privatized than in the US.

Despite my criticisms, this is a study worth reading by agrifood researchers if only to understand the value of bringing different social science perspectives to bear on agrifood analysis. One can argue that Henke didn't quite get it right but he has demonstrated that STS and ethnomethodological approaches can produce useful understanding of what goes on in our field, in the way science gets applied to agricultural production.

Open Access This article is distributed under the terms of the Creative Commons Attribution Noncommercial License which permits any noncommercial use, distribution, and reproduction in any medium, provided the original author(s) and source are credited.

\section{Author Biography}

William H. Friedland is Professor Emeritus/Research Professor at the University of California, Santa Cruz. His interests have been focused on commodity systems analysis, globalization, conventional agrifood systems, and the growth of alternative agrifood movements. 